\title{
Learning, Unlearning, and Relearning Together: Unmasking Power in a Students as Partners Program using Collaborative Autoethnography
}

\author{
Sakinah S. J. Alhadad, Daniela Vasco, Jude C. Williams, Pauline Dizon, Rachel L. Kapnias, Saira B. Khan, \\ Hayley Payne, Bronte C. Simpson and Chantelle D. Warren ${ }^{1}$ \\ Griffith University, Australia
}

\begin{abstract}
We interrogated a students as partners $(\mathrm{SaP})$, co-curricular program that focuses on supporting student learning. To center power and equity in $\mathrm{SaP}$, the program was grounded in social design-based experiment methodology. We considered the manifestation of power and equity beyond higher education, to that of broader socio-political contexts. Collaborative autoethnography (CAE) was used to garner a richer understanding of student-staff experiences of the program. Through CAE, power emerged as central to our collective experiences, and a recognition that power asymmetry in students as partners programs is complex and multi-layered. We found that to address power imbalances in these programs requires considered strategies and intentional designs. Further, CAE, in and of itself, can be a powerful way to foster self-awareness, mutual trust, respect, and the acknowledgement of others in student-staff partnerships. We conclude by recommending the importance of deliberate design for equity and power towards consequential learning and transformational change.
\end{abstract}

Keywords: Students as partners; social design-based experiments; collaborative autoethnography; equity; intersectionality

\footnotetext{
${ }^{1}$ Dr. Sakinah S. J. Alhadad, Learning Futures \& Griffith Institute for Educational Research, Griffith University Daniela Vasco, School of Education and Professional Studies \& Griffith Institute for Educational Research, Griffith University Dr. Jude C. Williams, Learning Futures, Griffith University

*Pauline Dizon, School of Environment and Science, Griffith University

*Rachel L. Kapnias, School of Applied Psychology, Griffith University

* Saira B. Khan, School of Engineering and Built Environment, Griffith University

*Hayley Payne, Griffith Business School, Griffith University

*Bronte C. Simpson, Queensland College of Art, Griffith University

Chantelle D. Warren, Learning Futures \& School of Applied Psychology, Griffith University

*Student-partner co-researchers

+ Author ordering statement: Alhadad (first author), Vasco \& Williams (equal $2^{\text {nd }}$ ), Dizon, Kapnias, Khan, Payne, \& Simpson, (equal $3^{\text {rd }}$ ),

Warren $\left(4^{\text {th }}\right)$.
} 


\section{Introduction}

Over the last decade, student-staff partnerships have garnered interest in higher education. Student-staff partnerships, also referred to as "students as partners" ( $\mathrm{SaP}$ ), is often defined as "a collaborative, reciprocal process through which all participants have the opportunity to contribute equally, although not necessarily in the same ways, to curricular or pedagogical conceptualisation, decision making, implementation, investigation, or analysis" (Cook-Sather et al., 2014, pp. 6-7). An underpinning value of this partnership approach is honoring the student voice as means to authentically progress educational research and practice; an endeavor rooted in democratic, civic citizenship, and social justice principles since the 1990s (CookSather, 2018). This axiology has emerged through evolving definition and practice of the ways in which students participate to inform educational planning and progress. Students are now positioned as more active collaborators in learning and teaching processes and practices. We posit that student-staff partnerships must be equity-centered for consequential learning and transformational change. In this article, we interrogate one such instance of a $\mathrm{SaP}$ initiative designed with equity and power as central. We employed collaborative autoethnography (CAE) among a subset of staff and student partners within the wider SaP program.

\section{Power and Equity as Elephants in the SaP Room}

Power is a complex construct that has structural, relational, dynamic, and multi-level dimensions which are pervasive in multiple contexts. Power dynamics are inseparable from socio-political contexts, such as the increasing nonlinearization of academia (Brooks et al., 2020), and the complex confluence of systems of inequity and privilege, such as racism, class bias, poverty, and gender prejudice (Nichols \& Stahl, 2019). These multi-level systemic structures of oppression and inequity interact and intertwine (Crenshaw, 1989) to influence the everyday entangled intersectional experiences of the marginalized, minoritized, disadvantaged, disempowered, and discriminated. These inequitable socio-political structures disproportionately influence individuals' sense of rightful belonging and learning as a consequence of cultural systems and structures (e.g., Nasir \& Vakil, 2017). We contend that the power asymmetry that exists in SaP in higher education cannot just focus on traditional structural power hierarchies (i.e., staff-student hierarchy power differential). Acknowledging the multilayered complexity of power, we assert that while power asymmetry can never be completely abolished, deliberate design to mitigate power asymmetry is necessary, and cannot be disentangled from socio-political contexts.

One way to address power asymmetry is to take an intersectional approach to individual engagement and community building. Creating conditions within which all students feel a sense of belonging or educational legitimacy - where students are "legitimately welcomed and positioned as powerful producers of new social futures" in their educational contexts (Calabrese Barton \& Tan, 2019, p. 617), thus imbuing a sense of "rightful presence"(Calabrese et al., 2019, p. 617). This requires broadening conceptions of diversity, and a critical stance towards defining equity. It also means deliberately considering the importance of access to resources and opportunities that recognize, respect, and value differences among people and contexts, while disrupting, rather than reproducing or reinforcing, systemic inequity and promoting justice-oriented futures (Calabrese Barton \& Tan, 2020). This stance highlights how legitimately belonging to a community of practice in any educational context is influenced and informed by historicized injustices in society, as much as within the structures of higher education, as intersecting with power hierarchies and practices (Squire \& Darling, 2013). Leveraging knowledge arising from epistemically diverse communities with current disciplinary expertise and knowledge, makes it possible for expansive opportunities for learning and becoming in ways that transforms education, beyond bridging of worlds (Calabrese Barton \& Tan, 2019).

Research suggests more work needs to be done in the context of SaP to address power asymmetry and its connections with broader social structures and systems. While SaP embraces the ethos of collaborative and equitable work between staff and students towards transformative practices, equitable power does not automatically happen. In a systematic review of outcomes of SaP initiatives (Mercer-Mapstone et al., 2017), one of the most prevalent negative outcomes reported by students was that partnerships reinforced pre-existing power inequalities based on traditional student-staff hierarchies (3\% of 65 studies; see Table 5 of Mercer-Mapstone et al., 2017). Conversely, a larger proportion of studies reported positive student outcomes as traditional power dynamics between students and staff shifted in SaP initiatives (19\% of 65 studies). At first glance, this relatively higher proportion of positive power shifts compared with reinforcement of power asymmetry might appear as a positive overall outcome in partnerships. However, it is important to note that: (1) negative outcomes appear to be underreported overall in the literature, a likely reporting bias whereby authors tend to report only positive results (Dawson \& Dawson, 2018); (2) the number of articles that discussed or reported about power in SaP studies was surprisingly low overall given the prevalence of inherent power asymmetry in SaP. If power is indeed a critical factor in genuine student-staff partnerships, then 
we would expect more references to power in the $\mathrm{SaP}$ literature. This relative disconnect of power from SaP designs is further evident by low numbers of studies engaging or empowering under-represented students (only $9 \%$ of 65 studies). These findings point to a crucial issue in SaP initiatives, where an ethos of equitable practices may not always be rooted in design and practices that create conditions needed to actively challenge power asymmetry for consequential learning and transformational change through SaP.

\section{Consequential Learning and Transformational Change Through SaP}

As a critical approach to $\mathrm{SaP}$, we are inspired by the research on consequential learning that highlights the importance of creating opportunities and conditions for meaningful engagement and production of knowledge, practice, and wisdom (Gutiérrez, 2012). Such practice, as those afforded by participatory design research rooted in justice (e.g., social design-based experiments), focuses on examining what matters to people, and how associated values, knowledge, and practices, through social activity, can allow for (re)imagining new transformative social futures (Bang \& Vossoughi, 2016; Gutiérrez \& Jurow, 2016). A deliberate design approach that cultivates transformative agency in students to disrupt traditional power notions of hierarchy in academia is central to social design-based experiments (SDBE), particularly among historically marginalized students. In the present SaP program (the "Leading Learning" program), we designed possible futures with this deep underpinning in SDBE, bringing together equity and learning in designing for consequential learning and transformative change. The view of equity as underpinning SDBE, focuses on challenging and transforming inequitable social systems, organizing pathways for expansive learning and identity development, in order to truly empower people in the community of focus with educational dignity and agency (Espinoza et al., 2020).

\section{Context: The Leading Learning Program}

The Leading Learning Program was initiated as a student-staff partnership, co-curricular program, with the collective focused on supporting student learning by leveraging the science of learning (e.g., Weinstein et al., 2018) in epistemically-inclusive ways. We adopted SDBE as a method within the framework of SaP in this program (Gutiérrez \& Jurow, 2016). To address the importance of epistemic diversity (Bang \& Medin, 2010; Warren et al., 2020), we sought to explicitly include student partners from a diverse, minoritized, underserved backgrounds and circumstances (e.g., cultural, racialized, LGBTQ+, first-in-family, etc.), whilst ensuring a diversity of disciplinary backgrounds (Mercer-Mapstone \& Bovill, 2020). This deliberate embracing of multiple ways of knowing (epistemic diversity), being, acting, and valuing was catalyzed by the applied use of the design thinking method (including: empathize, define, ideate, prototype, test) for collective interrogation of the science of learning toward co-developing resources to support student learning in epistemically-inclusive ways.

Expressions of interest were invited from students who had been involved in supporting student learning and/or experience at least once. This recruitment strategy was intentional to prevent the inadvertent selection of 'elite' students. Our initial analysis of student demographics and academic achievement as proxies of 'elite' subsections revealed that our wide-cast recruitment net included students with a wide-range of academic achievement, and a common desire to be involved in supporting other learners at the university (e.g., volunteering at orientation, peer mentoring). In the expressions of interest form, we stated our values in how we approached intersectionality as broad, diverse, and constitutive and asked them to share, as much as they were comfortable, their intersectional identities. This critical approach to intersectionality and act of axiological surfacing is necessary to develop critical trust (particularly in acknowledgement of socio-political trust and solidarity), and can also "support ethical designs, consequential learning, and accountability to participants" (Uttamchandani, 2020, p. 9). The program was designed for emergence to honor students' input for change in the process itself. Acknowledging that equity is inextricably connected with systemic societal disadvantages, the timeline of the program was negotiated and sometimes renegotiated with students, along with how and when the learning, reflections, and co-design work could occur.

SDBE requires empirical study to truly empower students, with the sense of social responsibility in understanding the people involved, within the situatedness of SDBE. Research within the program was approved by Griffith University Human Research Ethics Committee (GU ref 2020/600). This article specifically focuses on the CAE, where a subgroup of the broader collective engaged in CAE to unpack our experiences in this program. The collective is a core team of 19 active student-partners and three staff-partners, with occasional networks of other staff and students participating. The CAE involves five student-partner volunteers, three staff-partners, and a critical friend, all of whom are women, and are from diverse disciplinary backgrounds 
(i.e., built environment, design, medical science, business, psychology, political science, education) and different levels of studies and professional work.

\section{Methods}

\section{Collaborative Autoethnography (CAE)}

CAE emerges from autoethnography, where a duo or team of researchers participate in the research process of autoethnography (Chang et al., 2012). Like autoethnography, CAE also focuses on self-interrogation, but with the added iterations of selfinterrogation done collectively and cooperatively. CAE challenges researchers to deeply embrace emotional self-reflexivity as a rich data source and as part of their journeys as researchers (Chang et al., 2012). Autoethnography researchers, however, caution against strictly focusing on emotional reflexivity as part of CAE as a narrow focus on reflexivity "may have unintended consequence of eclipsing other visions of what autoethnography can be" (Anderson, 2006, p. 374). Instead, some authors argue that this rich description of personal experience should be combined with systematic analysis in order to understand the broader socio-cultural experiences (Ellis, et al., 2011). Hernandez and colleagues (2017, p. 251) encapsulates, CAE gives us "permission to make our shadow selves visible in our scholarship in a distinctive analytic style". CAE is a democratic research process underpinned often by social justice and equity, enabling researchers to interrogate in safe, supportive ways, complex and sensitive issues (e.g., Brock et al., 2017). As a multivocal, rigorous research endeavor, multiple auto-ethnographers engage each other in data collection. They complement, contradict, and probe each other as peers, thereby challenging "singularity of perspective through intersubjectivity and multivocality" (Hernandez et al., 2017, p. 252). These democratic values and processes of CAE fit well with the structures and ethos of SaP.

\section{Figure 1}

A Concurrent Collaboration Model in Collaborative Autoethnography, Adapted for SaP Based on Ngunjiri et al. (2010, p. 7)

\section{Phase 1: Preliminary Data Generation}

Elicit questions from students to trigger themes of collective reflections in $\mathrm{CAE}$

\begin{tabular}{l} 
Phase 2: Subsequent Data Generation: CAE Collective Reflection session \\
Collective reflections based on thematic topics in (1) \\
Phase 3: Data analysis and interpretation: Iterative, dialogical exploration of data and reflection and writing \\
\hline Individual data review and coding \\
\hline Individual and group meaning-making and outlining \\
\hline Phase 4: Report writing \\
\hline
\end{tabular}

Figure 1 illustrates the iterative, narrative, analytical process we engaged in for CAE, adapted from Ngunjiri and colleagues (2010). The team triggered the CAE process by eliciting questions of interest from student-partners (Phase 1). In Phase 2, we engaged in a collective reflection session based on the themes that emerged from the questions in Phase 1, and reflected individually after the session as part of the CAE process. In CAE, the data collection, analysis, and interpretation are an iterative 
rather than a linear process. The subsequent intermittent meetings held in Phase 3 provides this opportunity to discuss, assess and reflect, which is again part of the data in CAE. These group discussions are crucial for an effective CAE process. This process was further analysed and reflected on through group meaning making and writing.

\section{Data Collection and Storage}

The student-partner volunteers were asked to share their reflections regarding their experience in the program. They were also asked to express their burning questions and curiosities regarding the design and planning of the Leading Learning Program which in turn guided the data collection. This first stage triggered the CAE process and centered their curiosity and needs for the CAE. Two staff-partners classified these questions into main themes, which were used as a guiding reflective framework for the collective reflections in Phase 2. This collective reflection session aimed to clarify our experiences based on the identified themes. This discussion was then transcribed, coded, and analysed. All discussions were in an online environment via Microsoft Teams, where the meetings were not only recorded, but textual messages and chat were possible, and data were shared with the whole team. This 'shared space' also facilitated the collaborative process as "When all members of your collaborative research team have equal access to data as well as knowledge of how to access data, you will practice the democratic principle of CAE" (Chang et al. 2012, p. 97). This democratic process included open and equal access to the data across everyone - staff and students. This enabled a sense of empowered agentic participation throughout the whole process, helped build trust between participants, and enhanced the depth of the CAE process itself.

\section{Coding (Phase 3)}

As collaborative autoethnography permeates several stages of this research, coding was also done from a collaborative lens, using Braun and Clarke's (2006) inductive thematic analysis methodology. Because the data collection was based on questions developed by the student-partners, and these questions were classified into big topics that became codes, there were some predefined codes. The transcript of the collective discussion about the main topics identified in the students' questions was divided into utterances. The coding of each utterance into the pre-defined codes was conducted by two students and two staff. For each utterance coded, some 'small codes' were also defined. Group discussion allowed for the whole group to achieve consensus for the coding of each utterance, as well as the identification and creation of new small codes from the original small codes defined in the first round of the coding process. The utterances were then also coded against the new small codes; this time by all five students. Decisions were discussed in a whole group meeting to achieve coding consensus.

\section{ENA Analysis}

Epistemic Network Analysis (ENA) is a method for epistemic ethnography (Shaffer, 2017). ENA allows for the identification and quantification of meaningful connections between codes in textual data. ENA uses a set of mathematical algorithms that conduct some dimensional reduction and rotation of the data, thereby creating a visual model. This model provides a visual representation of the connections made in the target discourse, which may facilitate discussion, and thus, promote inference and interpretation of results in a collaborative environment. In an ENA, the associations between the codes are represented by an edge (link) between the corresponding nodes. The size of the nodes represents the frequency of code in the discourse, and the strength of the associations between codes are represented by the width of the edges. ENA is particularly relevant to evaluating $\mathrm{SaP}$ in a CAE context, as it allows a visual comparison of which codes were more strongly mentioned and connected by students or staff. This visualization facilitates easy identification of the participation in the discussion by staff and students, as well as the identification of the frequency of the topics that were brought up. These insights, as revealed by visualized patterns, are otherwise hidden in large amounts of transcripts or text (Alhadad, 2018). In addition, the ENA also contribute to the CAE as the visualization facilitates the discussion of the results as a group. To fit the ENA, we used the rENA package (Marquart et al., 2018) in R. We used a slide-window approach with the window of four utterances.

\section{Results and Discussion}

\section{Thematic Analysis from Students' Questions (Phase 1)}

Three out of five students provided a total of ten questions. These questions were classified using thematic analysis. The three themes identified were related to Power, Design, and Growth. The same question could refer to one or more themes. For instance, "Was the team satisfied with the overall quality of work produced by the student partners? If there was any inadequate work produced, was this addressed and how?" refers to Power; "Many students ended up having to step back partially or 
completely from the program due to personal issues arising, was this something that was initially factored into the project planning?" refers to Design; "Do you think the program will be useful for students' future careers?" refers to Growth; and "Did the program go as you planned, or did it change at all based on how students interacted with the content and learning science knowledge?" refers to both Power and Design.

\section{Coding (Phase 3)}

Through the questions developed by the students, three main codes were identified: Power, Design, and Growth. These codes were related to "positive" and "negative" experiences. For instance, Power was linked to utterances about collaboration and mentorship, how initial power imbalances were felt, and how they subsequently shifted. During group discussions, four codes were further identified - these were related to the three predefined codes: two related to perception of others (Social comparison; Embracing of epistemic diversity) and two related to perceptions of self (Self-doubt; Building confidence). Note that for both perception of others and of self, each was associated with a micro-code with a more "negative" connotation, Social comparison and Self-doubt, as well as a micro-code with a more "positive" connotation, Embracing of epistemic diversity and Building confidence.

\section{ENA Analysis}

ENA revealed that Building Confidence (Perception of Self) and Design were grouped together in the first quadrant. Codes related with Perception of Others (Social Comparison and Embracing epistemic diversity) are in the second quadrant. Power and Growth are in the third quadrant, whilst Self-doubt (Perception of Self) is isolated in the fourth quadrant. We focused on the differences between the networks obtained from the discourses of students versus staff. Results show that the networks are quite similar for both groups (Figure 2, top). For both groups, most of the connections are between Power and the other predefined codes, Growth and Design, as well as one of the new codes related to Perception of Others, Embracing epistemic diversity. Even though the centroids (point of balance) of both networks are slightly different, with the centroid for the student network $\left(\mathrm{C}_{\mathrm{x}}=0.11,95 \% \mathrm{CI}=[-0.09,0.31]\right)$ being in the right side of the network and the centroid for the staff network being in the left $\left(\mathrm{C}_{\mathrm{x}}=-0.19,95 \% \mathrm{CI}=[-0.32,0.28]\right)$, they are quite close and their confidence intervals highly overlap $(t(30.53)=$ $0.79 ; p$-value $=0.43$, Cohen's $d=0.24)$. This shows that even though both networks are very similar, students tend to give slightly more weight to codes in the first and fourth quadrants than the staff, who tend to give more weight to codes in the second and third quadrants than students. This is confirmed by the comparison of both networks in Figure 2 (Bottom).

The student group made slightly stronger connections among the new codes, as well as between Power and the new codes regarding Perception of Self, Building confidence and Self-doubt (Figure 2, bottom, blue lines). In particular, students made stronger links between Self-doubt and all the other codes. Conversely, the staff group seemed to make more connections between Growth and Embracing epistemic diversity, as well as the other predefined codes, Power and Design (Figure 2, bottom, red lines). Further, the staff group also seemed to make slightly more connections between Power and Embracing epistemic diversity.

Even though the ENA showed that overall, the pattern and strength of connections were similar for both students and staff, the students brought up new themes in the whole group discussion that were not identified previously in the questions classified solely by staff. Although there are connections of initial themes with these new themes, they were made mainly as a response to students' comments. Therefore, the CAE process allowed the students to have a 'voice' in data analysis and interpretation, enabling the enrichment of the connections and topics. 


\section{Figure 2}

Epistemic Network Analysis of Codes in Collective Reflection Session

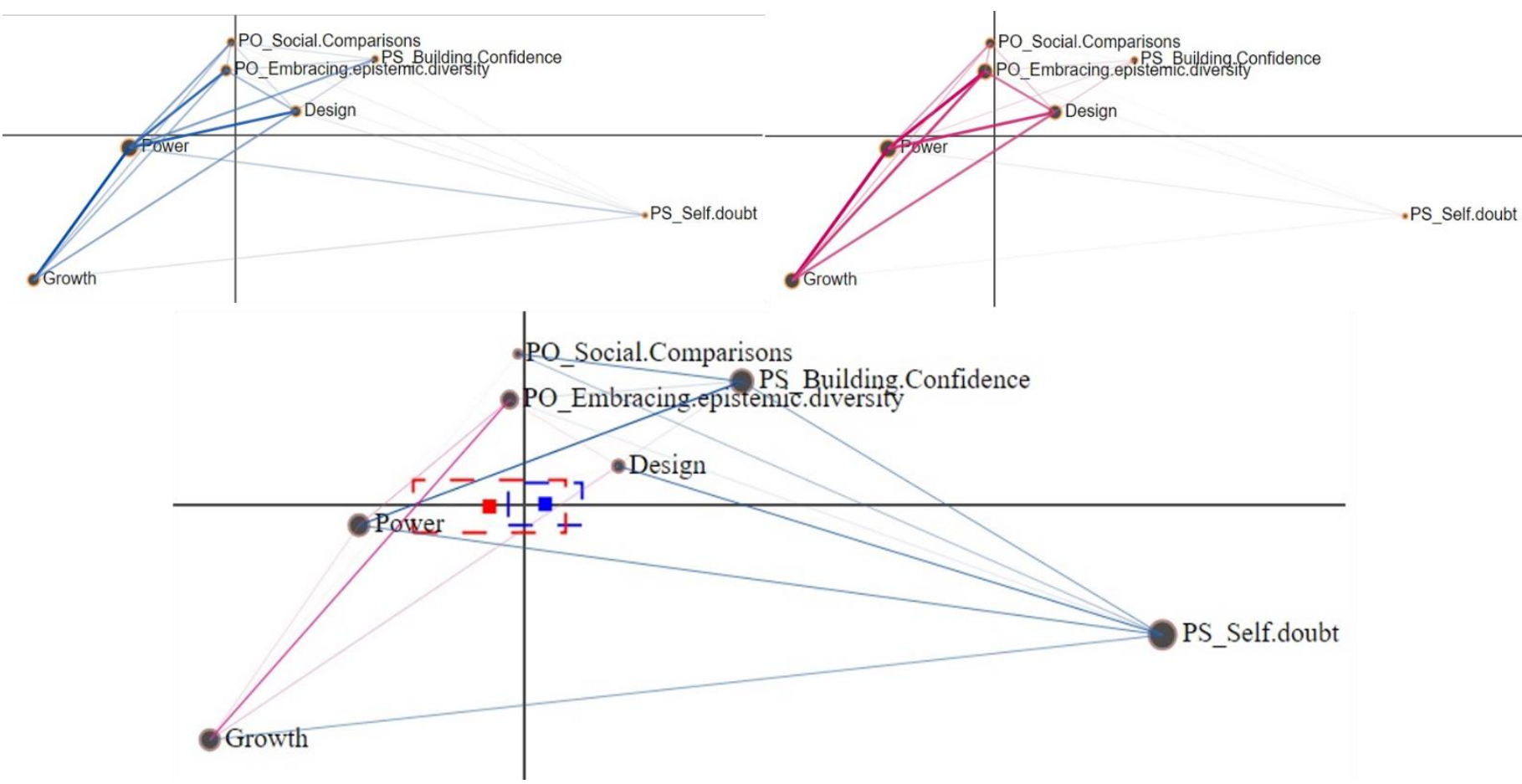

Notes: (Top) ENA students [Left] and ENA staff [Right]. (Bottom) Comparison ENA student and ENA staff, as well as the centroid (square) and respective 95\% confidence interval (box), in blue for the student' ENA and red for the staff's ENA. The blue color means that the students-partners made stronger connections, while the red color means that stronger connections were made by the staff-partners.

\section{Emergent Findings from Collaborative Autoethnography}

Emergent findings (numbered below) from the collaborative autoethnography affirm and provide depth and nuance to the ENA results. Note that quotes here are primarily from the collective reflection session in Phase 2 unless otherwise stated.

\section{Affirming existence of and shifting power asymmetry.}

Following from the thematic codes guiding the first collective reflections session as part of the CAE, we found ourselves focusing largely on discussions of power. We began by interrogating power in the context of SaP in higher education. These discussions affirmed consistent notions of inherent power asymmetry between staff and students and imbued by hierarchical structures, relations, and norms at universities. Both student and staff-partners noted the power shifts occurring over the course of the program:

... at the beginning it definitely felt more separated. So, definitely the staff leading the students. But there was such a big focus on we are all peers and we are all collaborators that throughout the time it kind of developed and it did feel more like okay we're all colleagues. [Student-partner3].

While power shifts were evident, there was agreement that it was difficult to unlearn expectations related to the staff-student traditional power asymmetry. Even though it was recognized that the experience here was different, the learned behaviour and normative expectations were perceivably different, and thus, were difficult to unlearn:

But I'm not gonna lie, there is still like a back-pinning kind of, well, no these are still the staff and they are leading the project and rightly so. You guys started the project, right? So, yeah, that that is my understanding of the power play [Studentpartner3]. 
This suggests that within the traditional structures of higher education, power asymmetries could be mitigated through design strategies, however may not be entirely abolished. Upon reflection, we considered the valence associated with power, and how power need not be viewed as inherently bad. From the student perspective, we considered how a redistribution of power is important for effective student-staff partnerships. Yet, we recognize that some element of that power asymmetry is useful for facilitating growth of learners, as long as there isn't an abuse of power (power used for good). The key consideration in power shifts is that they are necessary and appropriate over time, such that (equal) reciprocity, as expected in SaP, can be achieved with educational dignity. This considers the role that staff can take as a mentor earlier in the SaP process to build knowledge, skills, and confidence in student-partners when traditional power dynamics still hold, thereby using 'power for good'. This context- and temporal-dependent view of power in SaP design challenges the false dichotomy of power asymmetry as inherently bad, and power symmetry as inherently good. The temporal-dependence of power can often be seen in the natural student lifecycle in higher education, whereby students later in their degree or programs are given more autonomy over their own learning process (e.g., research project choices in Honours). We propose that these shifts of power could occur much sooner in the student lifecycle, normalizing supported learner agency via partnerships within their course or unit learning experiences.

\title{
2. Power in SaP cannot be disentangled from socio-political power contexts and experiences.
}

For students in particular, self-doubt was a strong theme that emerged. Post-session individual reflections revealed deeper insights into this:

\footnotetext{
During the session the topic of self-confidence and self-worth was explored. Feelings of self-doubt was shared between most of my peers... I personally felt not worthy of being in the program... I was surprised to hear that this was also felt by others in the group, when experiencing these feelings I didn't consider that anyone else in the group would be feeling the same way. This has really highlighted that everyone has their own vulnerabilities and perspectives, and this is why having a supportive, caring and inspiring environment to work in is so important [Student-partnerl].
}

We then found ourselves interrogating perceptions of power, particularly in relation to self-doubt, through the lens of our gender, and subsequently, racialized gender. When a student-partner voiced insecurities about their self-perceptions of intelligence and capabilities, a staff-partner pondered as to whether that sense of self-doubt may have arose through perceptions of capabilities as novices, not knowing each other, or from gendered power differentials:

\begin{abstract}
As the program was designed by, well, essentially [Staff-partner3], but with some input from [Staff-partner1] and myself and we all know each other pretty well um there was already some degree of power in terms of our understanding what we were doing compared to your understanding of what we were doing, you know? Then, how much was the project affected by the fact that the students didn't know each other and would take a bit of time to feel a sense of collective amongst each other, as well as a collective with academic staff? This interests me as well as the gender thing, you know? [Staff-partner2].
\end{abstract}

Discussions that ensued interrogated power differentials from other socio-political and epistemic domains:
... as a woman of color I honestly felt more comfortable and welcome in this space because [Staff-partner3] was there taking the lead on this project. Um that made a huge difference to me actually because I have been struggling a lot um being um in so many spaces where I'm constantly dealing with white men, no offense. Um, so, it's been really nice. And the fact that um all three of you [female] lead academics in this project, um, you really cared to make us feel welcome in this space and have our voices heard and were always holding space for all of us to contribute - [Student-partner5].

Colleagues then pondered on the complex entanglement of different sources of power, privilege, and epistemic diversity in relation to how we negotiate academic spaces for learning and epistemic growth. Reflections highlight valuing and respecting multiple ways of knowing, how this embraces epistemic diversity, and enabled a sense of personal growth in recognizing individual strengths and experiences as we work together. Student-partners 1 and 4 synthesize this complex entanglement in their reflections:

I was very overwhelmed just coming from a XX and XX [disciplinary] background even though I am very personally interested in [different discipline] and things like that. I just felt almost that I wasn't worthy of being a part of the group because I didn't have any grasp on anything that was going on. But um I just felt like it was just such a supportive environment that even though I didn't feel at the start that I had the knowledge, or if I didn't quite grasp something, that I could ask for help which is something that I've never really experienced at university before... like in a group being able to actually express my reflections and my opinions I think just being in such a safe environment, and being supported by like academics we're all obviously peers and colleagues but at the time I was seeing it very 'academics' and 'students' but I think it's just been so great to see everyone's different almost perspective but also experiences um because I think in [my disciplines] it's very honed 
in plus being a white female I think being able to see everyone's point of view and everyone's opinions is just being invaluable really [Student-partner 1$]$.

\begin{abstract}
...I totally understand from some students maybe knowing more going into it, I knew quite a bit of the topics from previous XX [disciplinary] classes and out of other interests and things. But I will say that I learned a lot more than I did in XX [disciplinary] classes...through discussions and other people's experiences. And I think having such an interdisciplinary team, it was very interesting to see the different perspectives, instead of being, like, okay, only from literature and only science based...everybody kind of has very different sort of backgrounds and I think learning from that and seeing everybody's skills... everybody else's kind of experiences and life, just life expressions in general being applied to the knowledge has been very very helpful [Student-partner4].
\end{abstract}

\title{
3. Power shifts enable transformative collaboration.
}

We also recognized that as power dynamics shifted, student-student and student-staff collaborative efforts became more equitable and genuinely collaborative (building on finding \#1). This experience allowed students to critically review previous group projects with a deeper sense of self-reflection to discover how they have influenced group power dynamics in the past and how they can work to establish more equitable peer-to-peer collaborations in the future:

So, in group situations, you kind of have this mindset, where if you want to get high grades, you feel you have to take control because you don't trust other people to do it. When we were planning the first student-led consultation, I just had this moment where, everyone was doing everything, and I think our first student-led meeting when [Staff-partner3] stepped away and I thought okay I'm going to have to talk up, and then somebody else did and I thought, wow this is great. Then, just from that moment it helped me to think I can trust other people and it made me think about the way I'd behaved in group assignments in the past as well, and, maybe in taking that control I wasn't allowing other people space to do things either and having more of a critical reflection there [Student-partner2].

Even though the discourse about power dynamics in SaP often focuses on student-staff power asymmetry, this process also helped the students become more aware of student-student power dynamics in group work, and subsequently adapting towards more democratic collaboration.

\section{Deliberate design for epistemic diversity may support epistemic growth and group cohesion.}

These discussions of epistemic diversity, sense of belonging and self-doubt in relation to prior knowledge, disciplinary backgrounds, among other sources, led to reflections on the role of design in creating the conditions for and supporting the embrace of epistemic diversity as central to knowledge building and production:

I wanted you to truly create it yourselves, um, from your perspectives and really, again honour where you come from at this particular point in time in your journey... acknowledging that everyone has their own individual journeys that they're going on, so while knowing that there are individual journeys, I also wanted to create an environment where we could also have a collective journey so to speak, right. So we're traveling together in some ways, and that we are all fellow travellers in this journey of leading learning and so that's where the considerations of equity and truly acknowledging and honouring individuals in the collective as part of it [Staff-partner3].

Many students noted in their individual post-session reflections that not only the Leading Learning program, but also the CAE process, helped with building their confidence:

Overall the session was a truly inspiring discussion that left me feeling that I could do anything I put my mind too [Studentpartnerl].

I felt empowered and inspired by everyone and I am truly appreciative to be able to work with such remarkable people [Student-partner4].

\section{Consciously holding space for mitigation of power asymmetry.}

Importantly, in relation to the nascent power asymmetry in SaP, staff-partners reflected on consciously having to refrain from over-engagement in discussions as they were aware that this would impact on power dynamics. In the same vein, staff-partners were also conscious of holding space (Wolpow et al., 2016) to build a relationship that upholds trust, compassion, and support, without judgement or control, whilst maintaining healthy boundaries: 
One of the things that I'm sitting here reflecting on is kind of like the multiple identities that I felt um I had in this. I remember in one of the early sessions, when we broke into breakout rooms and we were designing, I really felt that conflict of identities. I'm so enthusiastic as a peer and as a learner in group... when I'm in a group environment I really get carried away but I was conscious, oh gosh keep your mouth shut because the students may view me as not being a partner or colleague and then perhaps give more value and worth to what I'm saying [Staff-partner2].

Yeah, absolutely. The number of times I told myself to just hold back, hold back, remember you're trying to, you know, again that, yeah, really recognizing that there is a power imbalance and if you spoke you would change that dynamic completely. I just wanted to be part of this discussion as a peer but because again acknowledging that power imbalance, if we keep talking that would completely change the power dynamics and therefore we are no longer holding space as colleagues based on the power imbalance. [Staff-partner3].

\section{Importance of intentionality of design to address power asymmetries.}

Student-partners found confidence in the design of the program which allowed all participants to arrive on an equal footing:

So, the way that the program was set up so that we all acquired that knowledge first and we're arriving at an equal footing, I think was really essential to having that comfortable dynamic and no one was really judging anyone if they didn't understand a concept because we're all on the journey together [Student-partner2].

Within the university environment, while students are engaging with and learning the same content, each individual arrives with varying degrees of prior knowledge resulting from different life experiences. In our context, designing with the intent for each student to begin the program with (more) equal background knowledge opened space for (more) equitable collaboration and input to an extent that may have not been achievable without the intentional knowledge building stage.

\section{CAE supporting learning, unlearning, relearning, and growing together.}

Throughout our collaborative autoethnography, we reflected on how we have been, and continue to learn, unlearn, relearn, and grow together. One staff-partner captured this essence in her critical reflection on her ways of being as an educator within the $\mathrm{SaP}$ and the wider higher education work, and how deliberate design and practice of mitigating power asymmetry towards consequential learning and transformative action was personally and professionally beneficial. She ponders on how this was situated within the SaP experience, and how she desires for this same approach in other higher education contexts:

I've been kind of reflecting on how if I took this approach in different experiences how that would have shaped dynamics or not and how similarly if I took some of the approaches that I take in some of my other settings and have used them here how that would have shaped my experience of this collective um group, and 100\% agree with everything else that's been sort of said in terms of the inspiration and the emergence that's kind of come around feeling invited and accepted into the group space and that liminal space experience that I've also felt that and I personally feel like I've grown so much as part of this experience and working with you all [Staff-partnerl].

This sense of continued reflections on power and growth beyond the context of SaP were evident in students' individual postsession reflections, citing how the collective reflective session itself also inspired growth and self-evaluation:

I felt out of sorts for a while after the session, almost unbalanced. Throughout the day, I found myself questioning my perception of others (and how others might perceive myself). I felt a need to reflect on the "whys" of my actions and words. A particular question - how does power define my interactions? - kept echoing inside [Student-partner3].

It was so empowering to hear from each individual their self-doubts and how they overcame these throughout the program. Sometimes in our society so heavily focused on independence and the individual, we become so stuck in our own worlds that we don't fully connect with others and allow growth through collective storytelling, human relationships and community [Student-partner2].

\section{Concluding Reflections and Implications}

Our commitment to understanding students' experiences in SaP as underpinned by SDBE reveals a number of implications.

First, our findings align with calls for considered strategies when designing for SaP in relation to equity (Bovill et al., 2016; Mercer-Mapstone \& Bovill, 2020; Mercer-Mapstone et al., 2021). Our approach to centering equity with considerations of entanglement with power and intersectionality manifested from the recruitment stage of student partnerships, and remained 
centered throughout the program. Centering, beyond simply including, was deliberate and consistently conscious in pedagogy, language, and relationship building, ultimately allowing for the modelling of epistemically-inclusive practice. The CAE revealed that considerations of power in higher education do not exist in a vacuum. Rather, power interplays with socio-political contexts and impacts individuals in whatever environments they inhabit, including learning in higher education. If SaP genuinely aspires toward empowering students for consequential learning and transformational change, then considerations of power need to go beyond inclusion and challenging traditional staff-student power hierarchies, with particular focus on power shifts over time. This reinforces the value of designing for rightful presence where students are not only welcomed but also positioned as powerful change agents of possible futures (Calabrese Barton \& Tan, 2019). Strategies could include enhancing power literacy by design (Goodwill et al., 2021), equity-centered, trauma-informed design (Bali \& Zamora, 2021; Harrison et al., 2020), or compassion by design as a means of recognizing and mitigating structures that hinder flourishing of the disadvantaged (Alhadad et al., 2020). We specifically emphasize the importance of approaching SaP by inclusion of these strategies by design, reinforcing the notion that power asymmetry and equity-centered SaP need deliberate, a priori design towards mitigating or abolishing inequities.

Moreover, deliberate consideration of our design decisions that impact on access, opportunities, personal sense of legitimacy, and belonging is imperative. Ultimately, at least in the present higher education context, starting power to empower rests with staff rather than students. Therefore, responsibility for design decisions to set the starting conditions for rightful presence in $\mathrm{SaP}$ is in the hands of staff. Just like in social justice movements, we should not expect the disempowered and oppressed to change the systems, staff in higher education must use their privilege of relative structural power to champion positive change in this way.

Secondly, CAE appears to be an effective mechanism for deepening our learning, unlearning, and relearning of power. We started this process by using CAE to interrogate our own experiences, only to find that the CAE process itself enabled deep reflections and challenging of our own assumptions and perceptions that we were not ourselves previously aware of. CAE appears to foster self-awareness, as well as deeper mutual trust, respect, and acknowledgement of others. Thus, we recommend that $\mathrm{CAE}$ is embedded in future $\mathrm{SaP}$ initiatives to support this critical reflection and growth beyond just a research tool. Further, we incorporate the use of ENA and its visualisations to support our collaborative autoethnography process. This use of ENA primarily to support our reflective process (Alhadad, 2018; Worsley et al., 2021) (rather than of analysis of research findings per se) is novel. Collectively, all authors found that our collaborative reflections were enhanced using ENA as it helped us interrogate and question our assumptions and understanding of each other, and in supporting our reflexivity beyond what we were able to engage in prior to introducing the ENA in our CAE. In our context, this unique combination of quantitative and qualitative methods within the CAE methodology we adopted led us towards deep(er) reflections.

Finally, we talk about power within SaP, highlighting the power asymmetry between staff and students, and the need to address that power imbalance through considered strategies. However, research within SaP needs to be cognisant of the traditional hierarchies within higher education research (Cook-Sather et al., 2018) that perpetuate power imbalance. This includes how we make inferences about research findings in the SaP literature, as well as explicit acknowledgement and inclusion of students as co-designers and co-researchers. One of us, Student-partner5, pondered on whether the project's outcomes will ultimately be inferred as attributable to staff, or whether readers would acknowledge students' roles as true partners and co-researchers in the emerged outcomes.

So, you, dear reader - have you noticed? Have you made these inferences based on implicit bias about traditional institutional hierarchies? The staff in this CAE have explicitly acknowledged the impact the students had on them in terms of growth - did you see it? 


\section{References}

Alhadad, S. S. J. (2018). Visualizing data to support judgement, inference, and decision making in learning analytics: Insights from cognitive psychology and visualization science. Journal of Learning Analytics, 5(2), 60-85. https://doi.org/10.18608/jla.2018.52.5

Alhadad, S. S. J., Warren, C.D., Bridgstock, R., Williams, J. C., Lupton, M., Burns, K., Cardell, E., Cook, H., Dobson, K., Easte, C. Logan, D., McPhail, R., Shuker, M. (2020, April 7). Prioritising care and compassion in learning and teaching during the COVID-19 crisis [Blog post]. https://blogs.griffith.edu.au/learning-futures/prioritising-care-and-compassionin-learning-and-teaching-during-the-covid-19-crisis/

Anderson, L. (2006). Analytic autoethnography. Journal of Contemporary Ethnography, 35(4), 373-395. https://doi.org/10.1177/0891241605280449

Bali, M., \& Zamora, M. (2021). The equity-care matrix: Theory and practice [Manuscript submitted for publication].

Bang, M., \& Medin, D. (2010). Cultural processes in science education: Supporting the navigation of multiple epistemologies. Science Education, 94(6), 1008-1026. https://doi.org/10.1002/sce.20392

Bang, M., \& Vossoughi, S. (2016). Participatory design research and educational justice: Studying learning and relations within social change making. Cognition \& Instruction, 34(3), 173-193. https://doi.org/10.1080/07370008.2016.1181879

Bovill, C., Cook-Sather, A., Felten, P. Millard, L., \& Moore-Cherry, N. (2016). Addressing potential challenges in cocreating learning and teaching: Overcoming resistance, navigating institutional norms and ensuring inclusivity in studentstaff partnerships. Higher Education, 71, 195-208. https://doi.org/10.1007/s10734-015-9896-4

Braun, V., \& Clarke, V. (2006). Using thematic analysis in psychology. Qualitative Research in Psychology, 3(2), 77-101. https://doi.org/10.1191/1478088706qp063oa

Brock, C. H., Borti, A., Frahm, T., Howe, L., Khasilova, D., \& Ventura-Kalen, K. (2017). Employing autoethnography to examine our diverse identities: Striving towards equitable and socially just stances in literacy teaching and research. International Journal of Multicultural Education, 19(1). http://dx.doi.org/10.18251/ijme.v19i1.1258

Brooks, S. D., Dean, A. S., Franklin-Phipps, A., Mathis, E., Rath, C. L., Raza, N., Smithers, L. E., \& Sundstrom, K. (2020). Becoming-academic in the neoliberal academy: A collective biography. Gender and Education, 32(3), 281-300. https://doi.org/10.1080/09540253.2017.1332341

Calabrese Barton, A., \& Tan, E. (2019). Designing for rightful presence in stem: The role of making present practices. Journal of the Learning Sciences, 28(4-5), 616-658. https://doi.org/10.1080/10508406.2019.1591411

Calabrese Barton, A., \& Tan, E. (2020). Beyond equity as inclusion: A framework of "rightful presence" for guiding justiceoriented studies in teaching and learning. Educational Researcher, 49(6), 433440. https://doi.org/10.3102/0013189X20927363

Chang, H., Ngunjiri, F. W., \& Hernandez, K. C. (2012). Collaborative autoethnography. Routledge.

Cook-Sather A. (2018). Tracing the evolution of student voice in educational research. In: Bourke R., Loveridge J. (Eds). Radical collegiality through student voice. Springer, https://doi.org/10.1007/978-981-13-1858-0_2

Cook-Sather, A., Bovill, C., \& Felten, P. (2014). Engaging students as partners in learning and teaching: A guide for faculty. Jossey-Bass.

Cook-Sather, A., Matthews, K. E., Ntem, A., \& Leathwick, S. (2018). What we talk about when we talk about students as partners. International Journal for Students as Partners, 2(2). https://doi.org/10.15173/ijsap.v2i2.3790

Crenshaw, K. W. (1989). Demarginalizing the intersection of race and sex: A black feminist critique of antidiscrimination doctrine, feminist theory, and antiracist politics. University of Chicago Legal Forum, 14, 538-554.

https://chicagounbound.uchicago.edu/cgi/viewcontent.cgi?article=1052\&context=uclf

Dawson, P., \& Dawson, S. L. (2018). Sharing successes and hiding failures: 'Reporting bias' in learning and teaching research. Studies in Higher Education, 43(8), 1405-1416. https://doi.org/10.1080/03075079.2016.1258052

Ellis, C., Adams, T. E., \& Bochner, A. P. (2011). Autoethnography: An overview. Historical Social Research, 36, $273-290$.

Espinoza, M. L., Vossoughi S., Rose, M., \& Poza, L. E. (2020). Matters of participation: Notes on the study of dignity and learning, Mind, Culture, \& Activity. https://doi.org/10.1080/10749039.2020.1779304

Goodwill, M., van der Bijl-Brouwer, M., \& Bendor, R. (Dec 2021). Beyond good intentions: Power literacy for service designers. International Journal of Design.

Gutiérrez, K. D. (2012). Re-mediating current activity for the future. Mind, Culture, \& Activity, 19(1), 17-21. https://doi.org/10.1080/10749039.2011.632056

Gutiérrez, K. D., \& Jurow, S. A. (2016). Social design experiments: Toward equity by design. Journal of the Learning Sciences, 25(4), 565-598. https://doi.org/10.1080/10508406.2016.1204548

Harrison, N., Burke, J., \& Clarke, I., (2020). Risky teaching: Developing a trauma-informed pedagogy for higher education. Teaching in Higher Education. https://doi.org/10.1080/13562517.2020.1786046 
Hernandez, K. C., Chang, H., \& Ngunjiri. (2017). Collaborative autoethnography as multivocal, relational, and democratic research: Opportunities, challenges, and aspirations. a/b: Auto/Biography Studies, 32(2), 251-254. https://doi.org/10.1080/08989575.2017.1288892

Marquart, C. L., Swiecki, Z., Collier, W., Eagan, B., Woodward, R. \& Shaffer, D. W. (2018). rENA: Epistemic Network Analysis (0.2.0.0). https://cran.rstudio.com/web/packages/rENA/

Mercer-Mapstone, L., \& Bovill, C. (2020). Equity and diversity in institutional approaches to student-staff partnership schemes in higher education. Studies in Higher Education, 45(12), 2541-2557. https://doi.org/10.1080/03075079.2019.1620721

Mercer-Mapstone, L., Dvorakova, S. L., Matthews, K. E., Abbot, S., Cheng, B., Felten, P., Knorr, K., Marquis, E., Shammas, R., \& Swaim, K. (2017). A systematic literature review of students as partners in higher education. International Journal for Students as Partners, 1(1). https://doi.org/10.15173/ijsap.v1i1.3119

Mercer-Mapstone, L., Islam, M., \& Reid, T. (2021). Are we just engaging 'the usual suspects'? Challenges in and practical strategies for supporting equity and diversity in student-staff partnership initiatives. Teaching in Higher Education, 26(2), 227-245, https://doi.org/10.1080/13562517.2019.1655396

Nasir, N. S. \& Vakil, S. (2017). Stem-focused academies in urban schools: Tensions and possibilities. Journal of the Learning Sciences, 26(3), 376-406. https://doi.org/10.1080/10508406.2017.1314215

Ngunjiri, F. W., Hernandez, K. C., \& Chang, H. (2010). Living autoethnography: Connecting life and research [Editorial]. Journal of Research Practice, 6(1), Article E1. http://jrp.icaap.org/index.php/irp/article/view/241/186

Nichols, S., \& Stahl, G. (2019). Intersectionality in higher education research: A systematic literature review. Higher Education Research \& Development, 38(6), 1255-1268. https://doi.org/10.1080/07294360.2019.1638348

Shaffer, D. W. (2017). Quantitative ethnography. Catcart Press.

Squire, V., \& Darling, J. (2013). The "minor" politics of rightful presence: Justice and relationality in city of sanctuary. International Political Sociology, 7(1), 59-74. https://doi.org/10.1111/ips.12009

Uttamchandani, S. (2020). Educational intimacy: Learning, prefiguration, and relationships in an LGBTQ+ youth group's advocacy efforts. Journal of the Learning Sciences. https://doi.org/10.1080/10508406.2020.1821202

Warren, B., Vossoughi, S., Rosebery, A. S., Bang, M., \& Taylor, E. V. (2020). Multiple ways of knowing: Re-imagining disciplinary learning. In: N. S. Nasir, C. D. Lee, R. Pea, \& M. McKinney de Royston (Eds.), Handbook of the cultural foundations of learning (pp. 277-293). Routledge.

Weinstein, Y., Madan, C.R., \& Sumeracki, M.A. (2018). Teaching the science of learning. Cognitive Research: Principles \& Implications, 3(2). https://doi.org/10.1186/s41235-017-0087-y

Wolpow, R., Johnson, M. M., Hertel, R., \& Kincaid, S. O. (2016). The heart of learning and teaching: Compassion, resiliency, and academic success (Rewrite). https://www.k12.wa.us/sites/default/files/public/compassionateschools/pubdocs/theheartoflearningandteaching.pdf

Worsley, M., Anderson, K., Melo, N., \& Jang, J. Y. (2021). Designing analytics for collaboration literacy and student empowerment. Journal of Learning Analytics, 8(1), 30-48. https://doi.org/10.18608/jla.2021.7242

\section{Please cite this article as:}

Alhadad, S.S.J., Vasco, D., Williams, J. C., Dizon, P., Kapnias, R. L., Khan, S. B., Payne, H., Simpson, B. C., \& Warren, C. D. (2021). Learning, unlearning, and relearning together: Unmasking power in a students as partners program using collaborative autoethnography. Student Success 12(2), 38-50. https://doi.org/10.5204/ssj.1934

This article has been peer reviewed and accepted for publication in Student Success. Please see the Editorial Policies under the 'About' section of the Journal website for further information.

Student Success: A journal exploring the experiences of students in tertiary education

Except where otherwise noted, content in this journal is licensed under a Creative Commons Attribution 4.0 International License. ISSN: 2205-0795 